\title{
Talk and Die Syndrome: An Unending Mystery
}

\author{
Steffy Stanly, Thota Tejasree, VLD Nandini, S Ponnusankar*
}

Department of Pharmacy Practice, JSS College of Pharmacy Udhagamandalam - 643001 . The Nilgiris, Tamil Nadu, INDIA. Jagadguru Sri Shivarathreeshwara University, Mysuru, Karnataka, INDIA.

\begin{abstract}
The Traumatic Brain Injury is one of the most leading cause of the increased mortality and morbidity rate in the current populace, which induces sub-dural hematoma, hence while talking itself the person will die and so nick named as 'Talk and Die Syndrome'. Interesting field in neurology, with very rare incidence rate and CT scan plays a golden role in the diagnosis of Traumatic Brain Injury.
\end{abstract}

Key Words: Talk and die syndrome, Epidural hematoma, Traumatic brain injury, Natasha case, Treatment.

\section{INTRODUCTION}

Talk and Die syndrome is usually caused by specific brain injury, epidural hematoma and fracture in the temporal lobe that is located near an artery in the head. Reilly et al ${ }^{1}$ was the first person to use the word 'talk and die' to report a subset of patients who died with head injuries, initially thought to a mild traumatic brain injury. ${ }^{2}$

Half of the trauma related deaths were associated with Traumatic Brain Injury (TBI) which is a root cause to talk and die syndrome leading to severe morbidity and mortality in children and young adults ${ }^{3}$ and $10-13 \%$ of the pediatric mortality rate is due to the head injuries. ${ }^{4}$ National Health Service stated that TBI is a "silent epidemic "of the developing countries. ${ }^{5}$

"Talk and Die" syndrome is usually a delayed bleed like an epidural or subdural hematoma and is almost always fatal unless caught early. According to a study by an Australian trauma center reported that $2.6 \%$ of the head injury deaths involved "talk and die" syndrome. ${ }^{6}$ In a retrospective study investigated the incidence of all mild head injuries is 1.5\% per year and 0.5-1 million patients with head injuries present in UK hospitals each year, of which majority of them are Minor Head Injuries (MHI) based on Glasgow Coma
Scale (GCS 13-15). ${ }^{6}$ About 27\%-60\% of the deaths are due to neurologic injuries in the trauma cases. ${ }^{7,8}$ The goal of this article is to summarize the interesting facts on the unending mystery of the rare condition talk and die syndrome along with its as clinical manifestation, diagnosis and management etc.

\section{ETIOLOGY AND RISK FACTORS}

Patients with minor head injuries accidently deteriorate due to intracranial complications and this phenomenon is called "Talk and Die" syndrome. The causes that lead to this syndrome or traumatic brain injury are represented in Figure 1. Rather than a single extreme incident, repeated blows may also result in brain injuries. ${ }^{9}$ Mr. Graffagnino, Director of Duke University Medical Center Neurosciences Critical Care Unit, stated that "at first, a patient can appear normal" but they have a bleed in the brain due to increased pressure and start experiencing typical symptoms of a TBI. ${ }^{10}$

\section{CLINICAL MANIFESTATIONS}

The main complication and foremost primary clinical manifestation is severe
DOI: 10.5530/ijopp.10.4.51

Address for correspondence: DR S Ponnusankar, Professor and Head, Dept. of Pharmacy Practice JSS College of Pharmacy, Udhagamandalam -643 001. The Nilgiris Tamil Nadu, INDIA.

Phone no: +91-94896 13428 Email Id: ponnusankarsivas@ gmail.com

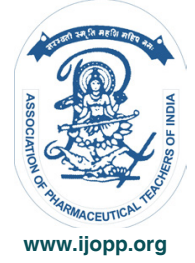




\section{Traumatic brain injury causes}

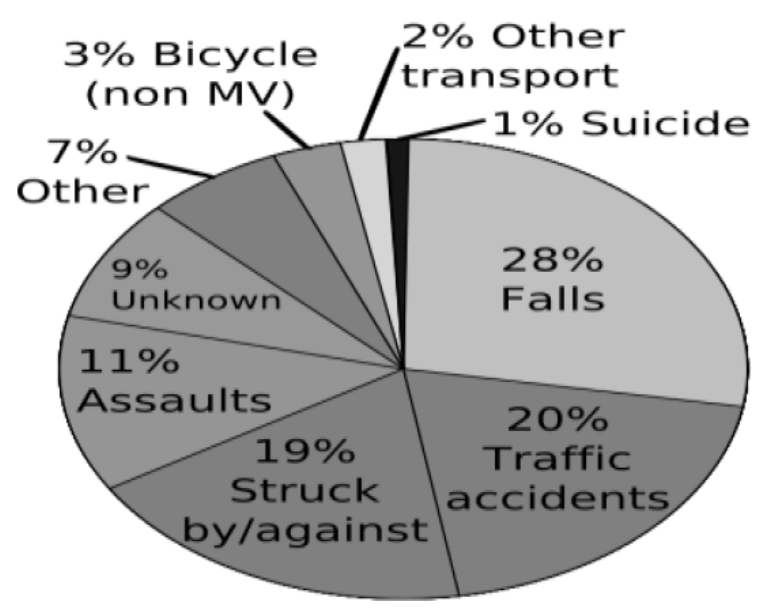

Figure 1: The causes of Traumatic brain injury.

headache followed by impaired speech and vision and then slip into coma ${ }^{11}$ and the person may not have any symptoms at first, but later they may complain of severe headache, weakness and confusion. ${ }^{12}$ Significance of intracranial mass lesions and raised Intra Cranial Pressure (ICP) in prognosis, outcome of patients who talked and deteriorated after head injury was first featured by Reilly's seminar paper in $1975 .{ }^{13}$ Moreover, intracranial hematomas and continued mass lesions lead to deterioration in TBI patients. ${ }^{14,15,16,17}$

Ramiro et al ${ }^{14}$ conducted a study on 838 patients with severe head injuries, of them 211 (25.1\%) patients talked at some time between trauma and subsequent deterioration into coma. Of these 211 patients, 89 (42.2\%) had hematoma, $46(21.8 \%)$ had epidural hematoma, 35 $(16.6 \%)$ had subdural hematoma and 41(19.4\%) didn't have any focal mass lesions, therefore in talk and die syndrome, intracranial hematomas are continued to be more significant. ${ }^{18}$

\section{CASE REPORT ON NATASHA}

Ms. Natasha Richardson, a 45year British born actress died on $18^{\text {th }}$ March 2009, due to fall on a Canadian ski slope. When she fell, everything seemed okay and there was no sign of injury and she was talking normally after the fall but later in her hotel room, she started experiencing severe headache within an hour and she was rushed to hospital and she died in hospital. This condition is usually caused by head injury called epidural hematoma, in addition the newspaper nicknamed it as "Talk and Die Syndrome". 19

\section{DIAGNOSIS}

A golden standard in evaluating patients after TBI is CT scan (a 3D X ray that provide cross-section images of anatomical structures) which would provide an indication of bleeding in brain ${ }^{20}$ and it identifies both intra-axial hemorrhage and extra-axial hemorrhage ${ }^{21}$ and all individuals with cognitive dysfunction should consider CT scan. ${ }^{22}$ According to various authors, patients with severe head injury should undergo CT scan for every $24 \mathrm{~h}$ or 3-5 days following the TBI and patients with mild- moderate head injuries CT scan should be obtained before discharge ${ }^{23}$ in addition forensic autopsy plays a crucial role to clarify the causal relation to the head injury. ${ }^{24}$

\section{MONITORING PARAMETRS}

Reilly P L et al ${ }^{13}$ stated that evidence based guidelines existed for management, but they are not taken into account because of various reasons including variation between individuals, portions of the brain and variation within time. Different monitoring techniques like Trans cranial Doppler, Jugular venous oxygen saturation and ICP waveform are used to focus on the therapeutic endpoints in individuals and targeting proper therapeutic management.

\section{TREATMENT}

Researchers claimed that some of agents can reduce evolution of brain injury and enhance the better patient outcome and developed an experimental model of brain injury which distinguishes the defusal of axonal injury by therapeutic manipulation. In addition to other studies, magnesium can improve outcome after diffuse brain injury. ${ }^{13}$ Further, the other treatment approaches include clot removal by surgery and manage with labetalol. ${ }^{25}$ In a review conducted by J E Tan et al ${ }^{18}$ stated that advanced age was associated with a poorer outcome, consequently the outcomes could be improved with early identification and continuous monitoring.

\section{CONCLUSION}

The talk and die syndrome on early diagnosis could create a pathway to treat the victims soon after the injury and to reduce the mortality rate accordingly. Adequate CT scan facilities and guidelines to manage the condition will add value to the treatment. 


\section{ACKNOWLEDGMENT}

The authors wish to thank the management of the JSS College of Pharmacy, Ooty for providing an opportunity to attend the "Workshop on Scientific Writing" organized by Dept. of Pharmacy Practice.

\section{ABBREVIATIONS}

CT scan: Computerized Tomography scan; GCS: Glasgow Coma Scale; ICP: Intra Cranial Pressure; MHI: Minor Head Injury; TBI: Traumatic Brain Injury.

\section{REFERENCE}

1. Reilly PL, Graham JD, Adams H, Jennet B. Patients with head injury who talk and die. The Lancet. 1975;30(8):375-7.

2. Kim J, Kemp S, Kullas K, Hitos K, Dexter MA. Injury patterns in patients who" talk and die". J Clin Neurosci. 2013;20(12):1697-701.

3. World Health Organization. Neurological disorders: Public health challenges. Geneva: WHO; 2007.

4. Zuccarello M, Facco E, Zampieri P, Zanardi L, Andrioli GC. Severe head injury in children: early prognosis and outcome. Childs Nerv Syst. 1985;1(3):158-62.

5. Davis R, Tait V, Dean J, Goldberg A, Rogers M. Head and spinal cord injury. In: Rogers M, editor. Textbook of Pediatric intensive care. Baltimore, MD: Williams and Wilkins; 1992;805-57.

6. Sultan HY, Boyle A, Pereira M, Antoun N, Maimaris C. Application of the Canadian CT head rules in managing minor head injuries in a UK emergency department: implications for the implementation of the NICE guidelines. Emerg Med J. 2004;21(4):420-5.

7. Hodgson NF, Stewart TC, Girotti MJ. Autopsies and death certification in deaths due to blunt trauma: what are we missing? Can J Surg. 2000;43(2):130-6.

8. Tien HC, Spencer F, Tremblay LN, Rizoli SB, Brenneman FD. Preventable deaths from hemorrhage at a level I Canadian trauma center. J Trauma. 2007;62(1):142-6.

9. Michael Schumacher draws attention to 'talk and die' brain injuries. 20132:58am [Available at: http://www.news.com.au/lifestyle/health/michael-schumacherdraws-attention-to-talk-and-die-brain-injuries/news-story/0f8f0d37410fddd002 d6791ba69e561b].
10. 'Minor' head injuries can turn serious rapidly, experts say. 2009. [Available at: http://edition.cnn.com/2009/HEALTH/03/18/brain.injury/index.html].

11. REUTERS, Sources: Mayo clinic, centers for disease control and prevention, news reports [Available at: https://knockedout-concussionsandsleep.wikispaces. $\mathrm{com} /]$.

12. VB Attorneys What is Talk and Die Syndrome? Available at: https://www. vbattorneys.com/faqs/what-is-talk-and-die-syndrome.cfm].

13. Reilly PL. Brain injury: the pathophysiology of the first hours. 'Talk and Die revisited', J Clin Neurosci. 2001;8(5):398-403.

14. Lobato RD, Rivas JJ, Gomez PA, Castaneda M, Canizal JM, Sarabia R. Headinjured patients who talk and deteriorate into coma. Analysis of 211 cases studied with computerized tomography. J Neurosurg. 1991;75(2):256-61.

15. Rockwold GL, Leonard PR, Najib MG. Analysis of management in thirtythree closed head injury patients who "talked and deteriorated" Neurosurgery. 1987;21(1):51-5.

16. Marshall LF, Toole BM, Bowers SA. The National Traumatic Coma Data Bank. Part2: Patients who talk and deteriorate: implications for treatment. J Neurosurg. 1983;59(2):285-8.

17. Rockswold GL, Pheley PJ. Patients who talk and deteriorate. Ann Emerg Med. 1993;22(6): 1004-7.

18. Tan JE, Ng I, Lim J, Wong HB, Yeo TT. Patients who talk and deteriorate: A new look at an old problem. Ann Acad Med Singapore. 2004;33(4):489-93.

19. PENN STATE NEWS. Probing Question: What is 'Talk and Die' Syndrome? [Available at: http://news.psu.edu/story/141342/2009/06/15/research/probingquestion-what-talk-and-die-syndrome].

20. Blackwell CD, Gorelick M, Holmes JF, Bandyopadhyay S, Kuppermann N. Pediatric head trauma: changes in use of computed tomography in emergency departments in the United States over time. Ann Emerg Med. 2007;49(3):320-4.

21. Kim JJ, Gean AD. Imaging for the Diagnosis and Management of Traumatic Brain Injury. Neurotherapeutics. 2011;8(1):39-53.

22. Health Policy and Clinical Effectiveness Program. Evidence based clinical practice guideline for management of children with mild traumatic head injury. Cincinnati, OH: HPCEP. 2000

23. Kochanek PM, Carney N, Adelson PD, Ashwal S, Bell MJ, Bratton S, et al. Guidelines for the acute medical management of severe traumatic brain injury in infants, children, and adolescents - second edition. Pediatr Crit Care Med. 2012;13(Suppl 1):S1-82.

24. Kibayashi K, Ng'walali PM, Hamada K, Honjyo K, Tsunenari S. Discrepancy of clinical symptoms and prognosis of a patient--forensic significance of "talk and die" head injury - Leg Med (Tokyo). 2000;2(3);175-80.

25. What is "talk and die" syndrome? By Brendan Borrell. 2009. [Available at: https://www.scientificamerican.com/article/talk-and-die-richardson/] 